\title{
Diagnóstico y tratamiento integral en pacientes con Amelogénesis Imperfecta. Reporte de un caso.
}

María del Carmen López Jordi, ${ }^{1}$

Esther Szwarc, ${ }^{2}$

\section{Resumen}

Objetivo: La Amelogénesis Imperfecta comprende un grupo heterogéneo de defectos del esmalte de origen genético, debidos a alteraciones en la formación del esmalte dentario, en calidad y/o cantidad. El diagnóstico se basa en la observación clínica, exámenes radiográficos, la historia familiar, el árbol genealógico y cuando es posible el diagnóstico genético. Se caracteriza por tener un amplio rango de presentaciones clínicas en ambas denticiones. Esta afección tiene un alto impacto en niños y adolescentes debido a que la carencia estética y la disfunción limitan su calidad de vida. La atención integral se convierte en un aspecto esencial y demanda una inteligente y necesaria interacción profesional, paciente $\mathrm{y}$ familia, la cual debe establecerse en forma temprana y de manera interdisciplinaria. Objetivo: Presentar un reporte de caso de un paciente de 11 años con Amelogénesis Imperfecta y diagnóstico clínico y radiográfico de tipo hipoplásico, apoyado en su historia familiar. El tratamiento integró varias etapas: uso de agentes remineralizantes a fin de restaurar los tejidos dentarios; ortodoncia para crear espacio para la erupción del canino retenido (13) y alineación de la arcada dentaria superior y rehabilitación dentaria con resinas compuestas y coronas metálicas fenestradas en oclusal. Conclusiones: El seguimiento por cinco años con una actitud muy positiva de la paciente hacia el mantenimiento de su salud, confirma que en el adolescente, una sonrisa saludable es importante en el desarrollo de la autoestima y las relaciones interpersonales.

Palabras clave: Salud bucal, Amelogénesis Imperfecta, genética, atención odontológica interdisciplinaria.

\footnotetext{
1.Profesora Mg. Directora Maestría en Ciencias Odontológicas-opción Odontopediatría. Facultad de Odontología. Universidad de la República. Uruguay. ORCID No: 0000-0002-9025-3188.

2 Profesor Agregado. Especialista en Odontopediatría. Facultad de Odontología. Universidad de la República. Uruguay.
} 


\section{Diagnóstico e tratamento integral em pacientes com Amelogênese Imperfeita. Relato de um caso.}

\section{Resumo}

A Amelogênese Imperfeita compreende um grupo heterogêneo de defeitos de esmalte de origem genética, que ocorre devido a alterações na formação de esmalte dentário, e podendo comprometer em qualidade e/ou quantidade do mesmo. O diagnóstico é baseado em observação clínica e radiográfica, história familiar, padrão genético familiar e quando possível, realização de uma investigação genética. Ela caracteriza-se por ter uma ampla gama de manifestações clínicas em ambas as dentições. Esta condição tem um alto impacto em crianças e em adolescentes, gerando um comprometimento social, a funçáo e consequentemente, limitando a qualidade de vida dos pacientes. O cuidado integral torna-se um aspecto essencial do tratamento, exigindo uma interação do profissional com o paciente e seus familiares, que deve ser estabelecida de forma precoce e interdisciplinar. Os objetivos do plano de tratamento devem abranger três aspectos: prevenção, restauração da estrutura dental e reabilitação estética. Objetivo: Paciente de 11 anos de idade, com amelogênese Imperfeita de tipo hipoplásico, segundo o diagnostico clínico e radiográfico e com base na história familiar. $O$ tratamento foi realizado em diversas etapas: uso de agentes remineralizantes na remineralizacão de tecidos dentais, tratamento ortodóntico para criar espaço para a erupção do canino retido e o alinhamento da arcada dentária superior, e por último, a reabilitação com resinas compostas e coroas metálicas fenestradas na superfície oclusal. Conclusão: Durante cinco anos de acompanhamento, o paciente tem demonstrado uma atitude muito positiva em relação à manutenção de sua saúde, confirmando-se que na adolescência, um sorriso saudável é importante no desenvolvimento da autoestima e das relações interpessoais.

Palavras chave: Saúde bucal, Amelogênese Imperfeita, genética, assistência odontológica integral.

Case report

\section{Diagnosis and comprehensive treatment for patients with Amelogenesis Imperfecta. Case report.}

\begin{abstract}
Amelogenesis Imperfecta is a diverse group of hereditary and heterogeneous enamel defects, due to alterations in the formation of dental enamel in quality
\end{abstract}

and/or quantity. Diagnosis is based on clinical and radiological findings, family history, family tree, and genetic diagnosis when it is possible. It is characterized by a wide range of clinical presentations in both dentitions. This condition has a 
high impact on children and adolescents, generates a very disadvantageous social performance since aesthetic problems and dysfunction limit their quality of life. Comprehensive care becomes an essential aspect and it demands a close and necessary professional, patient and family interaction, which must be established early and in an interdisciplinary way. Objective: We present a patient with Amelogenesis Imperfecta, 11 years old, with a clinical and radiographic diagnosis of hypoplastic type, based on her family history. The treatment integrated several stages: use of remineralizing agents in order to restore

\section{Introducción}

En los últimos años se han logrado importantes avances en la comprensión de los mecanismos biológicos y etiológicos de las enfermedades orales, así como en el desarrollo de terapéuticas efectivas. Hoy día surge un nuevo paradigma de salud, el biopsicosocial, con implicaciones tanto para la clínica, la investigación y las políticas de salud. Este nuevo paradigma agrega a la salud y su atención, el concepto de calidad de vida y el reconocimiento de los determinantes funcionales y sociales sobre la misma. La Federación Dental Internacional (FDI), en el marco de su Asamblea General 2016, propone una nueva definición de Salud Bucal, como concepto dinámico, de naturaleza subjetiva y muy influenciada por el pasado social y cultural de la persona "1,2 "La salud oral es multifacética e incluye la habilidad para hablar, reir, oler, saborear, tocar, masticar, tragar y transferir una serie de emociones a través de las expresiones faciales con confianza y sin dolor, incomodidad ni enfermedad del complejo craneofacial". La dental tissues, orthodontics to create space for the eruption of the retained canine (13), and the alignment of upper dental arch, and rehabilitation with composite resins and metal crowns fenestrated in occlusal. Conclusion: The five year follow- up, with a very positive attitude of the patient toward the maintenance of her health, suggests that in adolescence, a healthy smile is important in the development of selfesteem and interpersonal relationships.

Key words: Oral health, Amelogenesis Imperfecta, genetics, comprehensive dental care.

mencionada definición y sus componentes son pertinentes a la problemática que motiva este trabajo, cuando las personas ven su desempeño social perjudicado ya que una disfunción sumada a una carencia estética limita su calidad de vida.

La Amelogénesis Imperfecta (AI) comprende un grupo heterogéneo de defectos del esmalte de origen genético, con alteraciones en el proceso de formación del tejido adamantino, en su calidad y/o la calidad. ${ }^{3}$ La prevalencia de AI varía geográficamente: de 1/700 en Suecia a 1/14.000 en Estados Unidos, afecta a ambos sexos y a dientes temporarios y permanentes. $^{4}$ La $\mathrm{AI}$ presenta distintos patrones hereditarios, puede transmitirse a partir de un patrón autosómico dominante (AD), por uno recesivo (AR), ligado al cromosoma $X o$ aún por mutación genética espontánea. ${ }^{5}$ Los principales genes candidatos a mutaciones causales de AI, son aquellos que codifican proteínas involucradas en la ruta de formación del esmalte, modulando la deposición mineral y el 
crecimiento del órgano del esmalte (AI no sindromática). Asimismo, pueden verse afectados otros tejidos orales y extra orales (AI sindromática). La complejidad del patrón de enfermedad sugiere la ocurrencia de mutaciones en más de 15 genes en la etiología de AIno sindromáticas siendo los más conocidos: amelogenina, enamelina, ameloblastina, tuftelina $y$ amelotina. ${ }^{3,6}$ Una reciente investigación identifica que en la ameloblastina se encuentra la más importante mutación y al ser la encargada de la generación de la primera fase del desarrollo del esmalte (secretora), su mutación genera un daño dental profundo. La segunda mutación descubierta es de la amelotina producida en la última fase de maduración del esmalte, cuando este debe calcificarse y endurecerse. ${ }^{7}$

El diagnóstico de AI se basa habitualmente, en la observación clínica, la historia familiar, el árbol genealógico y exámenes paraclínicos. La radiografía panorámica puede dar los primeros indicios: defectos en el tamaño dentario, presencia de dientes retenidos etc. y las periapicales aportan mayor precisión respecto a: trastornos de la mineralización, falta de contraste entre esmalte y dentina, y tamaño de cámara pulpar. Actualmente, el diagnóstico genético no se puede aplicar sistemáticamente, siendo un recurso muy importante para la investigación. La AI se caracteriza por tener un amplio rango de presentaciones clínicas (fenotipos). ${ }^{9}$ Varios sistemas de clasificación han sido propuestos basados en: la herencia, la histopatología y las características dentarias específicas. La clasificación de Witkop 4 distingue cuatro tipos de AI basándose en el fenotipo que pueden subdividirse en 15 categorías en función del patrón hereditario. Recientemente, se propuso que la herencia sea el principal factor de clasificación dando lugar a una nueva clasificación propuesta por Neville et al. (2016) ${ }^{10}$ a) Amelogénesis imperfecta hipoplásica, b) Amelogénesis imperfecta hipocalcificada, con sus variantes hipomaduración e hipocalcificación y c) Amelogénesis imperfecta con taurodontismo (AI hipomadura/ hipoplásica). Se propone avanzar hacia un nuevo sistema de clasificación, basado en el modo de herencia, con discriminantes secundarios que incluyan fenotipo, bases moleculares y resultados bioquímicos, que en el futuro serán de directa aplicación en el tratamiento del paciente. ${ }^{10}$ El diagnóstico diferencial de AI con otros trastornos del esmalte no es sencillo dada la inespecificidad de algunas de las manifestaciones siendo importante distinguir la fluorosis dental, la hipomineralización molarincisiva (MIH) y otras displasias del esmalte no generalizadas. La AI se ha asociado con diferentes alteraciones dentarias (discoloraciones, microdoncia, agenesias) y también con maloclusiones (mordida abierta y mordida cruzada) que pueden resultar de alteraciones en los mecanismos eruptivos, hábitos de succión y pérdida de dimensión vertical. ${ }^{11}$ Los diferentes autores reconocen que la mayor queja de los pacientes afectados de $\mathrm{AI}$, son la insatisfacción estética y la alta sensibilidad dentaria, lo que obliga a abordarlo con una visión integral. Esta condición se acompaña de problemas psicológicos y ausencia de seguridad, debido a la apariencia de los órganos dentarios. ${ }^{12}$ Autores como Coffield et al. ${ }^{13}$ señalan que el impacto originado por ser portador de AI, es comparable al generado por condiciones sistémicas que afectan severamente la salud. Esto implica para el paciente, deterioro de la 
percepción de su imagen, autoestima y confianza. La carencia estética impone al individuo retos sociales de interacciones e incluso auto percepción negativa. ${ }^{14-15}$ Las anomalías dentarias, presentes en la AI, colocan a quienes la poseen en desventaja psicosocial y en definitiva perjudica su calidad de vida. Por ser una afección que se presenta desde la erupción de los dientes e interferir en tantos campos de la salud, la atención integral debe brindarse en forma temprana reconociéndose como un factor clave en la calidad de la misma. ${ }^{16}$

En el tratamiento influyen factores como: edad, tipo y grado de severidad de la afección, situación intraoral, otros factores de riesgo, contexto socioeconómico y cultural etc. El diagnóstico temprano asegura un plan de tratamiento adecuado cubriendo tres aspectos: prevención, restauración tisular-dentaria y rehabilitación estética. Es importante motivar al paciente y sus padres hacia una completa rehabilitación bucal. El plan de tratamiento preventivo es esencial debido a aspectos funcionales y para lograr un impacto psicológico positivo, incluye: instrucciones de higiene oral, utilización sistemática de dentífricos fluorados $\mathrm{y}$ consejos dietarios. La higiene oral puede resultar dificultosa en pacientes con AI por sensibilidad durante el cepillado por lo que se recomienda un cepillo de cerdas suaves y agua tibia para el enjuague lo cual mejora los síntomas y la efectividad del procedimiento. Actualmente los productos que potencian la restauración tisular promoviendo su remineralización tienen muy buena receptividad en la profesión y sus éxitos clínicos son evidentes. Tal es el caso del complejo de Caseín Fosfopéptido y Fosfato de Calcio Amorfo (CPP-ACP) comercializado como Recaldent ${ }^{\mathrm{TM}}$ (GC America) incluido en cremas para aplicación tópica y gomas de mascar que promueven la remineralización dentaria. En condiciones de $\mathrm{pH}$ neutro hay una disolución de los cristales de hidroxiapatita, liberando iones de calcio, fosfato e hidroxilo al fluido oral que conduce a una sobresaturación de la solución precipitando los minerales nuevamente en la superficie dentaria lo que puede considerarse una remineralización. Se ha demostrado que ese incremento de iones biodisponibles lo proporciona la aplicación con ACP-CPP uno o dos veces al día durante 10 días. ${ }^{17}$ Con la aplicación de cremas que contienen CPP-ACP, los péptidos son capaces de interactuar con las proteínas salivales resultando esenciales durante el proceso de remineralización. ${ }^{18}$ Por otro lado, el CPP-ACP es útil en reducir la hipersensibilidad dentaria produciendo la oclusión de los túbulos dentinarios. En pacientes con AI mayores de seis años se indica la presentación que combina caseín fosfopéptido-fosfato de calcio amorfo con fluoruro (900 ppm F-), representado por CPP-ACFP (MI Paste Plus) que según Reynolds (2008) ${ }^{19}$ genera un incremento de iones calcio y fosfato biodisponibles. Esta acción sinérgica aumenta la incorporación del fluoruro resultando en una mayor mineralización del esmalte sub-superficial comparado con la utilización del fluoruro solo. Un beneficio adicional de este compuesto, lo constituye la mejora en la apariencia estética de las opacidades, según. Reynolds una mayor concentración de calcio, fosfato y fluoruro en la superficie adamantina conduce a su difusión en el espesor de todo el esmalte, resultando en niveles más altos y homogéneos de mineralización. ${ }^{20}$

Luego de culminada la etapa rehabilitadora, el paciente debe seguir cumpliendo un plan preventivo 
importante para el éxito a largo plazo de las restauraciones estéticas ya que requerirá tratamiento adicional, reparador, a intervalos variables a fin de mantener el cierre marginal como parte del mantenimiento de la salud..$^{21} \mathrm{El}$ tratamiento rehabilitador inicial, debe ser conservador, respetando lo más posible los tejidos dentarios utilizando para las restauraciones cementos de ionómero de vidrio de alta densidad o combinados con resinas de fotocurado. En la medida que estas restauraciones se mantienen y la sensibilidad se reduce en forma considerable, se comienza a realizar restauraciones de resina compuesta logrando una mejor estética y durabilidad. Es importante lograr un buen grabado dado que hay un alto porcentaje de fallas en la adhesión de las restauraciones en pacientes con AI especialmente en el tipo de amelogénesis con hipocalcificación.

\section{Caso clínico}

Paciente de 10 años de edad, sexo femenino, consulta en 2012, a la Carrera de Especialización en Odontopediatria, Facultad de Odontología, Universidad de la República, Uruguay. En la Historia Clínica Institucional está registrado en forma expresa el Consentimiento Informado firmado por la madre de la paciente luego de recibir ambas información adecuada, suficiente y continua para los procedimientos diagnósticos, terapéuticos, registro fotográfico y su eventual publicación. El motivo de consulta es la falta de estética de sus dientes, que según relato del paciente y su familia, comenzó con la erupción de dientes permanentes y también gran sensibilidad dentaria frente a alimentos, bebidas y cepillado bucal. La historia describe que su nacimiento fue por parto natural presentando pautas de crecimiento y desarrollo normales. Al momento de la consulta en nuestra Clínica, se observa que la niña presenta un desarrollo físico-psico-social de acuerdo a su edad cronológica, sistémicamente sana (controlada regularmente en salud) y no se encuentra bajo tratamiento médico.

Antecedentes odontológicos. El tiempo de erupción de la dentición temporaria y mixta fue normal y relata experiencia de caries en los dientes caducos. Su dieta es cariogénica con alto contenido de jugos y alfajores. Su experiencia odontológica fue buena y es derivada a la Facultad por los profesionales tratantes para establecer un diagnóstico de su condición. Presenta múltiples restauraciones con Ionómero de vidrio y aparatología ortopédica (se retira al ingresar a la Especialidad).

Antecedentes familiares. Bisabuela paterna, tío abuelo y padre presentaron la misma condición bucal (dientes oscuros y pequeños), posee un hermano menor odontológicamente sano. Actualmente el padre es portador de prótesis completa. Se aprecia un entorno familiar con buen clima educativo y social y cumplidor en sus consultas.

Historia actual: La paciente relata alta sensibilidad a los cambios térmicos que le dificulta la higiene y la alimentación. También informa sobre sus problemas estéticos, se advierte que no quiere mostrar los dientes por lo que cuesta que sonría y temor al examen bucal por miedo a sentir dolor al contacto con instrumentos, aire o agua. 
Examen clínico y radiográfico 2012 (Figuras 1-3). Presenta 27 dientes permanentes erupcionados, Índice de Higiene Oral Simplificado (HIOS) de 1.7, Índice de caries/diente (CPOD) de 6, Índice de caries/superficie (CPOS) de 13, no erupción del canino superior derecho, alteraciones en estructura del esmalte,

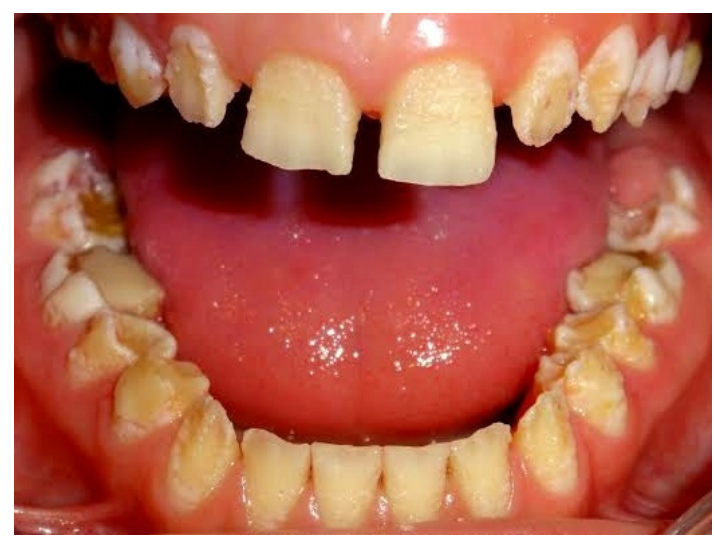

Figura 1. Examen clínico 2012.

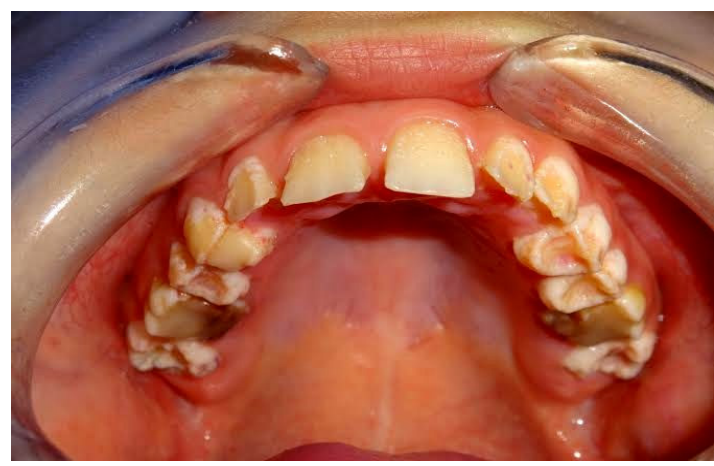

Figura 2. Examen clínico 2012.

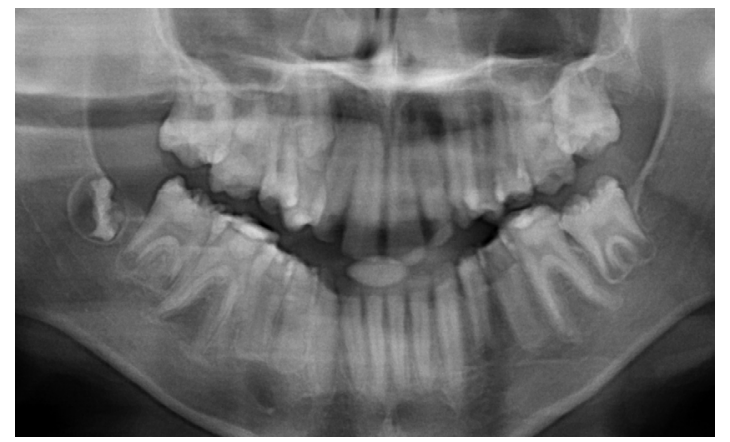

Figura 3. Ortopantomografía 2012. dientes de color amarillento, bordes incisivos atricionados, ausencia de puntos de contacto y superficies de aspecto relativamente rugoso, restauraciones plásticas en: 14, 16, 26, 36, 44 y 46 (defectuosas), línea media desviada a la derecha, "overjet" y "overbite" de apariencia normal. Al examen funcional: respiración nasal, fonación normal, deglución adulta y masticación bilateral y alternada. Radiográficamente se aprecia el número de dientes correcto, el 13 retenido y el germen del 48, desarrollo dentario y erupción normal y se identifica que no existe otra patología ósea ni malformaciones salvo en el espesor de los tejidos dentarios, muy fino en algunas piezas, pero con contraste casi normal del esmalte con la dentina.

Diagnóstico: Amelogénesis Imperfecta (leve) no sindrómica, de tipo hipoplásica. La etiología hereditaria podría determinarse probablemente ligada al cromosoma $X$ o de tipo autosómica dominante de acuerdo a las características de su árbol genealógico. Tratamiento 2012-2014, 2015: 1) TERAPIA BÁSICA: Enseñanza de higiene oral con cepillo blando, dentífrico fluorado 1.500 ppm y enjuague bucal con agua tibia, Indicación de MI Paste Plus dos veces al día, remotivación a la paciente y familia en cada sesión; control de biofilm y control de dieta. 2) TERAPIA REHABILITADORA: Sellado con Ionómero de vidrio modificado con resina en las zonas dentarias hipoplásicas $(17,15,14,13,24$, $25,26,27,37,35,34,33,43,44,45,47)$, coronas de acero fenestradas en oclusal y resinas en 16, 26, 36, 46 (Figuras 4 y 5), controles periódicos estrictos (semanales y quincenales). La telerradiografía (Figura 6) y el cefalograma muestran que es una paciente en crecimiento, con perfil 


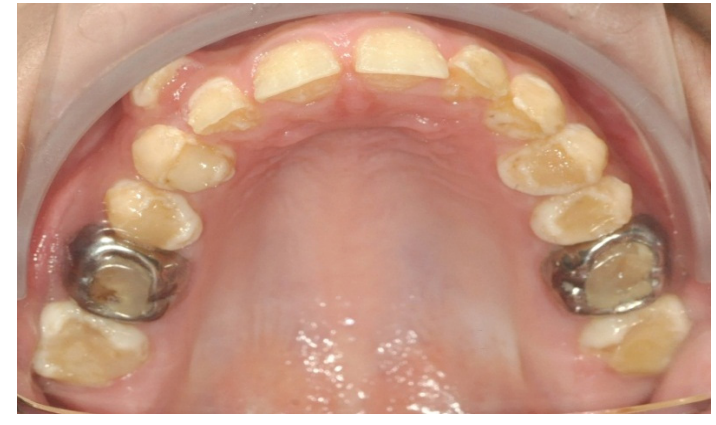

Figura 4. Maxilar superior 2015.

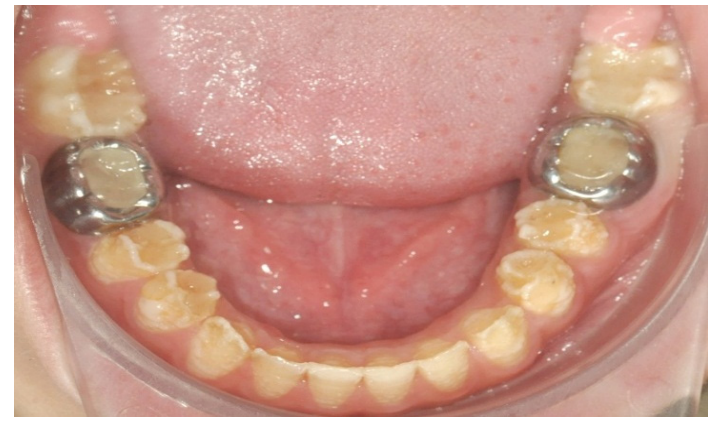

Figura 5. Maxilar inferior 2015.

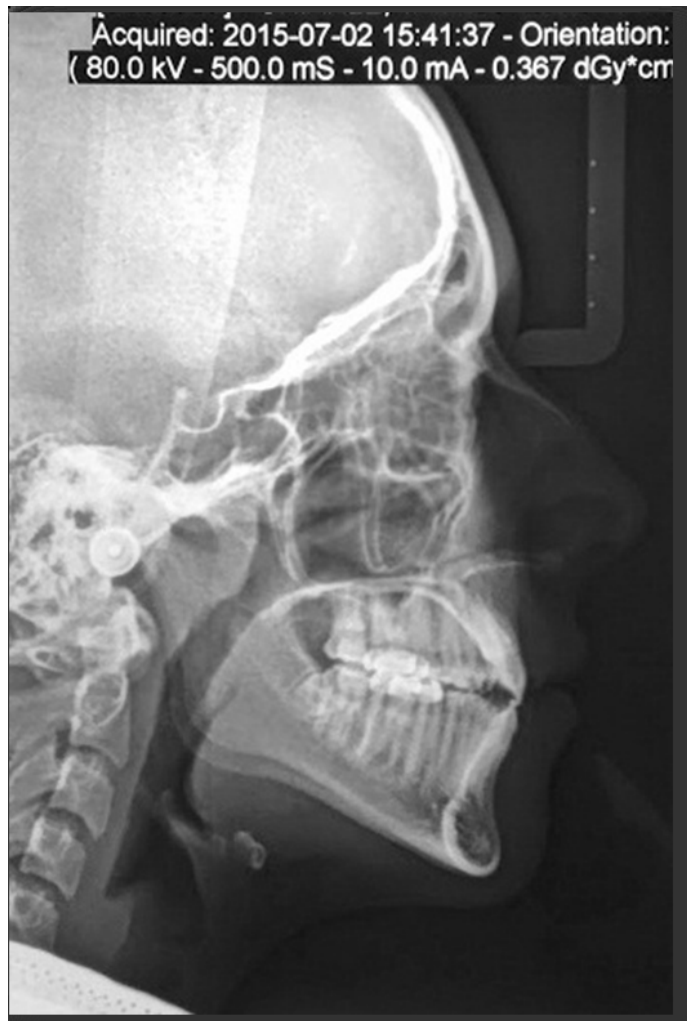

Figura 6. Telerradiografía. recto, crecimiento rotacional posterior (dólico-facial suave), Clase I molar, Clase II ósea, "overbite y overjet" disminuido (tendencia a mordida abierta), 13 retenido, ángulo interincisivo aumentado e incisivo inferior levemente retruido lo que llevó a la colocación de aparatología ortodóncica en el 2015, a fin de crear espacio para el canino, y alinear la arcada superior. (Figura 7).

Tratamiento 2017: retiro de aparatología ortodóncica. 1) terapia básica: Remotivación a la paciente y su familia, control de biofilm, dentífrico fluorado 1500 ppm, aplicación domiciliaria de MI Paste Plus 2 veces al día, a fin de remineralizar las lesiones blancas que se evidencian al retiro de los brackets. 2) terapia rehabilitadora: restauración de todos los dientes con resina de fotocurado, controles quincenales estrictos (Figuras 8, 9). Seguimiento del desarrollo de terceros molares e interconsulta con

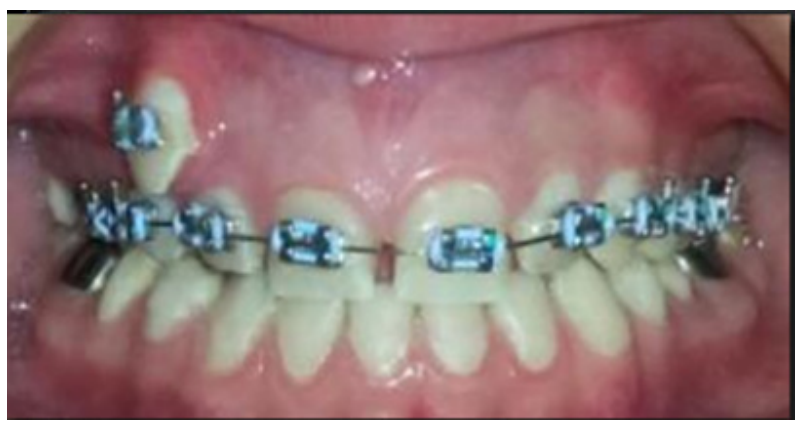

Figura 7. Aparatología ortodóntica 2016.

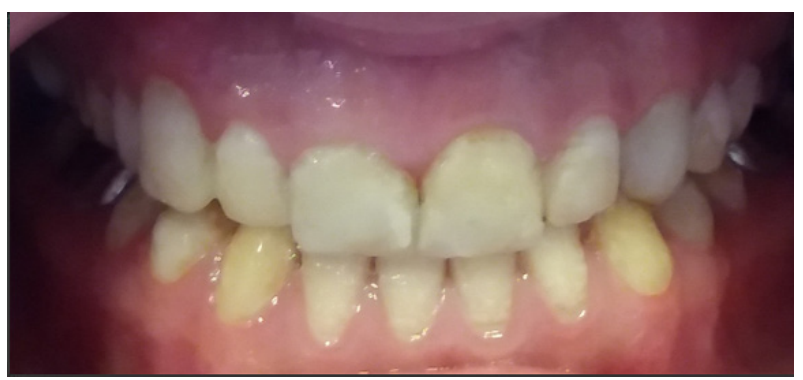

Figura 8. Control clínico 2017. 


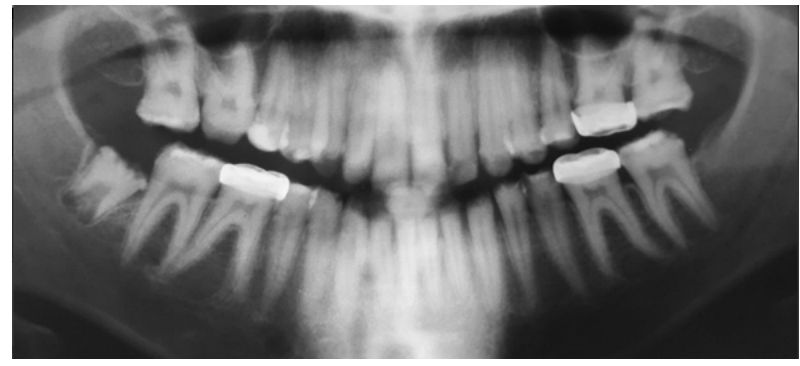

Figura 9. Control radiográfico 2017.

equipo interdisciplinario, aparatología ortodóncica y rehabilitación definitiva.

\section{Discusión}

La AI constituye un grupo de afecciones heterogéneas tanto clínica como genéticamente, caracterizadas por defectos en el esmalte. En nuestro país, no existen estudios de prevalencia respecto a dicha patología. Habitualmente, se derivan a la Especialidad de Odontopediatría de nuestra Facultad, por ser un centro de referencia a nivel nacional, casos con patologías de formación de tejidos dentarios, lo cual puede darnos una falsa idea de su frecuencia. La paciente que presentamos, fue derivada en su etapa de dentición mixta con la finalidad de establecer un diagnóstico que explicara la falta de estética de los dientes permanentes recién erupcionados y su gran sensibilidad. Nuestro diagnóstico primario, fue AI de tipo hipoplásico.

Dada la importancia de la herencia en su etiología y transmisión, los estudios genéticos son la mejor base para un diagnóstico certero de esta afección. Recientemente, a través de estudios clínicos, genéticos y moleculares de familias afectadas de $\mathrm{AI}$, se están estableciendo correlaciones fenogenotípicas en este grupo de anomalías. Se espera que los mismos colaboren en un mayor conocimiento de la afección para que puedan contribuir a mejorar su pronóstico y faciliten su aplicación. Debido a las dificultades tecnológicas disponibles en nuestro medio y la escasa posibilidad de acceso a exámenes de ese tipo, la anamnesis, el examen clínico y radiográfico continúan siendo los más utilizados para establecer su diagnóstico. La AI de tipo hipoplásica, se caracteriza por inadecuada deposición de matriz del esmalte, en cambio la mineralización, cualquiera sea la cantidad de matriz presente, se produce en forma adecuada y con apropiado contraste radiográfico del esmalte con la dentina subyacente. De acuerdo a la clasificación de Neville, nuestra paciente presenta una AI de tipo hipoplásico con mayor semejanza a la de patrón punteado generalizado. Las fositas se encuentran desparramadas a lo largo de la superficie dentaria y no se correlacionan con un patrón de alteración medioambiental. El esmalte entre las fosas es de espesor, dureza y coloración normal, presenta atrición ligera de bordes incisales y falta más marcada de esmalte en la superficie oclusal, no característica de un patrón localizado. Los aspectos fenotípicas de la paciente, de acuerdo a la citada clasificación, mostraría correspondencia con el tipo de herencia autosómica dominante. Dado que, en el árbol genealógico de la paciente se relata como antecedente más remoto haber sido presentada por su bisabuela paterna, un tío abuelo (que no lo transmitió a su descendencia y solo tuvo hijos varones) y su padre, se evaluó que también podría ser ligada al cromosoma $X$, ya que esta forma no se transfiere de individuos masculinos 
a masculinos y todas las hijas del hombre afectado son portadoras del defecto genético. (La paciente es única hija mujer del matrimonio y solo tiene un hermano que no presenta AI). El no recordar otros antecedentes del árbol genealógico y la no realización de exámenes genéticos, mantienen dichos diagnósticos como hipotéticos.

Otro dato a resaltar es que según la paciente y su familia, no presentó AI en la dentición caduca (relata experiencia de caries). Dado que se resalta en la literatura que AI afecta ambas denticiones, deducimos que debido al reducido espesor de esmalte en la dentición primaria (menor discoloración) se pudo enmascarar dicha patología y no ser diagnosticada tempranamente por el odontólogo. Las diferentes anomalías dentarias como ser: microdoncia, ausencias congénitas, calcificaciones pulpares e, hipercementosis no están presentes. ${ }^{8,11} \mathrm{Se}$ constató un canino permanente superior retenido y ausencia de algunos puntos de contacto por desgastes e incisivos atricionados pero no se asoció a mordida abierta (aunque hay tendencia a ella), sin pérdida dedimensión vertical. No presentó alteraciones gingivales de consideración, salvo en el inicio del tratamiento una ligera gingivitis relacionada a biopelícula, por defecto de cepillado.

En cuanto al tratamiento, incluyó todas las etapas que clásicamente describe la literatura. En la fase preventiva, debemos destacar, la positiva respuesta tanto de la paciente, como de su familia. Fue fundamental el empleo, como agente remineralizante, del complejo CPP-ACP (Recaldent TM GG-América). ${ }^{17-20} \mathrm{Su}$ uso adecuado, provocó un rápido descenso de la hipersensibilidad dentinaria, el cual se demostró en el descenso del índice de higiene oral simplificado de 1.7 a 0.6 en las primeras consultas. También es de destacar la modificación de la dieta cariogénica que presentaba por otra más saludable, a pesar de estar transitando la adolescencia. La etapa rehabilitadora fue adaptada en forma individual a las particularidades de la paciente. Se comenzó con restauraciones con vidrio ionómero y se fueron aportando soluciones más estéticas y funcionales de acuerdo a la respuesta y crecimiento de la paciente. Es de destacar, que en la rehabilitación de los molares 16-26-36 y 46, se optó por coronas de acero fenestradas en oclusal y resinas. Como ventajas de su utilización, señalamos no solamente restituir puntos de contacto proximales, sino también, colaborar a no alterar más la dimensión vertical permitiendo un mejor control de los contactos en relación céntrica y excéntrica comparados con las coronas metálicas totales. En el sector anterior se utilizaron resinas, con buenos adhesivos dentinarios, procurando soluciones cada vez más estéticas, no teniendo problemas con la adhesión, tanto de las restauraciones como con los brackets para la reubicación del canino retenido y posterior alineación de la arcada superior, a pesar de que se relatan habituales fallas de grabados principalmente en los casos de AI del tipo hipocalcificadas. No obstante, cuando los márgenes de las restauraciones se volvían visibles, eran reparados en los controles, lo cual contribuía a la satisfacción de la paciente.

Consideramos de gran importancia, que en la progresiva resolución exitosa de este caso, y que aún requerirá nuevas etapas, la influencia de factores sociales y funcionales positivos de la paciente y su entorno fueron fundamentales (familia funcional, estilos de vida saludable, 
acceso a la salud, etc). Estos aspectos son contemplados en el nuevo paradigma biopsicosocial de la salud bucal, como factores moderadores y determinantes conductoras, a los efectos de promover y mantener la salud bucal. ${ }^{1-2}$

\section{Conclusiones}

La amelogénesis imperfecta, constituye un grupo de trastornos heterogéneos, tanto clínicos como genéticos, de naturaleza hereditaria. Las múltiples alteraciones que produce alcanzan la salud bucal, la emocional y en definitiva a la calidad de vida, lo que hace necesaria la atención integral del paciente. El abordaje interdisciplinario, con la colaboración temprana, estrecha y mantenida en el tiempo de los profesionales de la salud, el paciente y su entorno familiar permitió en la paciente presentada optimizar los resultados del complejo tratamiento. El plan de tratamiento se basó, como recomienda la literatura, en factores como edad, tipo de defectos y necesidades individuales. Se priorizó restablecer la estética y controlar la sensibilidad a fin de generar bienestar general y emocional reforzando la autoestima del paciente, que se hizo evidente por la aceptación del tratamiento con una sonrisa alentadora. El éxito a largo plazo dependerá de la adherencia a los controles periódicos estrictos, para lo que se requerirá la motivación constante de la paciente y su entorno familiar, lo cual se viene cumpliendo satisfactoriamente en el caso clínico presentado en este artículo.

\section{Referencias bibliográficas}

1. Lee JY, Watt RG, Williams DM, Giannobile WV. A New Definition for Oral Health: Implication for Clinical Practice, Policy and Research. J Dent Res. 2017; 96: 125-127.

2. FDI's definition of oral health, October 2016. Recuperado de: http://www.fdiworlddental.org/oral-health/ vision-2020/fdis-definition-of-oral-health

3. Poulter JA, Murillo G, Brookes SJ, Smith CE, Parry DA, Silva S, Kirkham J, Inglehearn CF, Mighell AJ. Deletion of ameloblastin exon 6 is associated with amelogenesis imperfecta. Hum Mol Genet. 2014; 23: 5317-24.

4. Witkop CJ Jr. Amelogenesis imperfecta, dentinogenesis imperfect and dentin dysplasia revisited: Problems in classification. J Oral Pathol. 1988; 17: 547-53.

5. Murillo G, Silva S, Mata M, Esquivel MJ. Amelogénesis Imperfecta. Probabilidad genética de expresión en futuras generaciones de familias costarricenses. Odovtos-Int. J. Dental S.C. 2014, 16: 71-86.

6. Prasad MK, Laouina S, El Aloussi M, Dollfus H, Bloch-Zupan A. Amelogenesis Imperfecta: I Family, 2 Phenotypes and 2 Mutated genes. J Dent Res. 2016; 95: 1457-63.

7. Smith C, Murillo G, Brookes SJ, Poulter JA, Silva S, Kirkham J, Inglehearn CF, Mighell AJ. Deletion of amelotin exons 3-6 is associated with amelogenesis imperfect. Hum Mol Genet. 2016; 25: 3578-87.

8. Koruyucu M, Bayram M, Tuna EB, Gencay K, Seymen F. Clinical Findings and long-term managements of patients with amelogenesis imperfecta. Eur J Dent. 2014; 8: 546-52.

9. Ortega Urzua O, Rodríguez P, Martínez Morales B. Análisis genético-clínico de una familia afectada con una malformación de esmalte dental. Rev Médica Chilena 2015; 133: 1331-40.

10. Neville BW, Damm DD, Allen CM, Chi AC. Abnormalities of teeth. En: Oral and Maxillofacial Pathology. 4th ed. St. Louis, MO: Elsevier Saunders; 2016: cap 2. 
11. Gadhia K., McDonald S., Arkutu N., Malik K. Amelogénesis imperfecta: an introduction. Br Dent J. 2012; 212: 377-9.

12. Poulsen S, Gjørup H, Haubek D, Haukali G, Hintze H, Løvschall H, Errboe M. Amelogenesis imperfecta-a systematic literature review of associated dental and oro-facial abnormalities and tact on patients. Acta Odontol Scand. 2008; 66: 193-9.

13. Coffield K, Phillips C, Brady M, Roberts MW, Strauss RP, Wright JT. The psychosocial impact of development dental defects in people with hereditary amelogenesis imperfecta. J Am Dent Assoc. 2005; 136: 620-30.

14. Murillo G, Morales F, Gamboa LC, Meza AM, López AC. Impacto emocional y en calidad de vida de individuos afectados por amelogénesis imperfecta. Odovtos-Int. J. Dent. Sc. 2015; 17: 73-85.

15. Parekh S, Almehateb M, Cunningham S. How do children with amelogénesis imperfect feel about their teeth? Int. J. Paediatr. Dent. 2014; 24: 326-335.

16. Montero J, Bravo M, Albaladejo A, Hernández LA, Rosel EM. Validation the Oral Impact Profile (OHIP14sp for adults in Spain. Med Oral Patol Oral Cir Bucal. 2009 1; 14: 44-50.

17. Lata S, Varghese NO, Varughese JM. Remineralization potential of fluoride and amorphous calcium phosphate-casein phosphor peptide on enamel lesions: An in vitro comparative evaluation. J Conserv Dent. 2010; 13: 42-6.

18. Huq NL, Myroforidis H, Cross KJ, Stanton DP, Veith PD, Ward BR, Reynolds EC. The Interactions of CPP-ACP with Saliva. Int J Mol Sci. 2016 9; 17: 915.

19. Azarpazhooh A, Limeback H. Clinical efficacy of casein derivatives: A systematic review of the literature. J Am Dent Assoc. 2008; 139: 915-24.

20. Reynolds EC, Cai F, Cochrane NJ, Shen P, Walker GD, Morgan MV. Fluoride and casein phosphopeptideamorphous calciumphosphate. J Dent Res. 2008; 87: 344-8

21. Markovic D, Petrovic B, Peric T. Case series: Clinical findings and oral rehabilitation of patients with amelogenesis imperfecta. Eur Arch Paediatr Dent. 2010; 11: 201-8.

Recibido: 05/01/18

Aceptado: 02/05/18

Correspondencia: María del Carmen López Jordi correo: dra.lopezjordi@gmail.com 